\title{
IMPLEMENTING "GREEN"ELEMENTS INTO THE SUPPLY CHAIN - THE LITERATURE REVIEW AND EXAMPLES
}

\author{
Paula Bajdor ${ }^{1}$ \\ Janusz K. Grabara ${ }^{2}$
}

\begin{abstract}
Almost every operating enterprise in the market has the supply chain. Depending on the size and nature of the enterprise, supply chain can take many forms, but the basic elements of each supply chain are as follows: suppliers, production and distribution together with the common links between them. Now, in the consciousness of nearly every organization that works to market is the belief that one of the determinants of its continuous development is the protection of the environment. Because of this, companies try, during their actions, to cause the least harm on natural environment. The following article presents the classic supply chain that occurs in manufacturing companies and how, the implementation of proposed solutions into it, may bring the result that classic supply chain will become more environmentally friendly and "green". Also, this article presents four companies operating in various sectors of the economy, together with the actions taken by them to minimize their negative impact on the environment. Presented enterprises can serve as an example for other companies trying to enter the arrangements and procedures, whose main purpose is to protect the environment by transforming their supply chain into Green supply chain.
\end{abstract}

Keywords: supply chain management, enterprises, green supply chain

JEL: M12

\section{The Classic Supply Chain definitions}

Currently, the "supply chain" term is defined by many authors who are experts in the field called "logistics". Each of them has created its own definition, however, despite to the large number of these definitions, they are fairly uniform. For example, R. Ganesh and T. Harrison, define the supply chain as ,a Network of facilities and distribution options that performs the functions of procurement of materials, transformation of these materials into intermediate and finished products, and the distribution of these finished products to customers" (Ganesha R., Harrison T.,1995). Very popular and well-known definition of the supply chain is also the definition given by M. Christopher: "The supply chain is a network of organizations involved, through links with suppliers and customers, in a various processes and activities which create an add-value formed by products and services offered/distributed/supplied to the final consumers"( Christopher M. 1998). The simplest and shortest definition is the definition given by D. Lambert, Stock J and L. Ellram, which says that ,a supply chain is the alignment of firms that bring products or services to market"(Lambert D et all. 2001). Similar to the definition given by M. Christopher is the definition saying that "The supply chain presents the network of companies and contractors who supply raw materials and components, reprocess them into semi-finished products and components, then produce one final product, and then allow to their consumption by a final consumer"(Bagchi P.K., 2000) given by PK Bagchi. On the other hand, Chopra S. and Meindl P., argue that: ,a supply chain consists of all stages involved, directly or indirectly, in fulfilling a customer request. The supply

\footnotetext{
${ }^{1}$ Paula Bajdor, Czestochowa University of Technology, e-mail: paula.bajdor@googlemail.com

${ }^{2}$ Janusz K. Grabara, Czestochowa University of Technology, e-mail: janusz@grabara.eu
} 
chain not only includes the manufacturer and suppliers, but also transporters, warehouses, retailers, and customer themselves"( Chopra S., Meindl P., 2003). According to this definition, there are four areas in the company, in which the decisions taken affect the ability of existing supply chain: production, localization, transport and information flows (fig. no. 1).

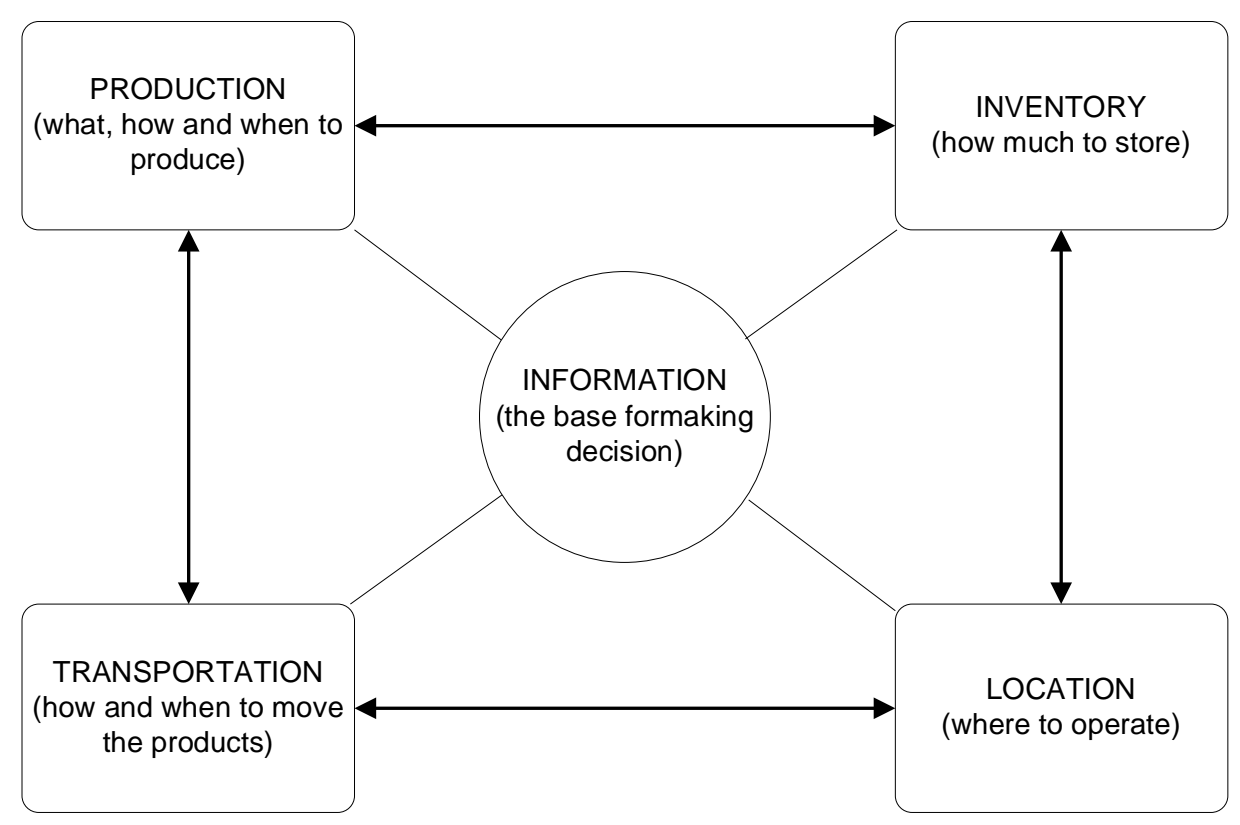

Fig. no. 1. - Five major factors in the supply chain.

Source: Author's elaboration based on Hugos M., „Essentials of Supply Chain Management”, John Wiley\&Sons, NJ 2011.

All these areas are defined by Chopra, S. and Meindl P., later M. Hugos has added a fifth element, which is ,performance drivers that can be manager to produce the capabilities needed for a given supply chain"(Hugos M., 2011). This definition is the broadest definition because it contains all the participants who work within the organization or are influenced by its actions. According to this definition, the supply chain may include items such as extraction of raw materials from the sources as well as after-sales customer service.

Another set of supply chain definitions are the definitions given by authors, who in comparison to the classical definitions, provide the more extended definitions. According to these authors, these definitions are as follows (Mentzer J., et all. 2001):

- The supply chain is a set of three or more organizations that are directly associated with the upper or lower flows of products, services, money and information between the source and the client,

- Basic supply chain includes the organization (company), vendor and customer, who are directly tied to the upper or lower flows of products, services, money and information,

- Extended supply chain includes the providers of direct suppliers and customers, direct customers, they are all related to one or more flows (lower and upper) of products, services, money and information,

- Final supply chain includes all organizations that are engaged in upper and lower flows of products, services, money and information from the original supplier until the last customer,

- A supply chain orientation is the recognition and identification system created by the organization and the strategic implications of actions and processes which are involved in the management of the flows within the supply chain,

- Supply chain management is "an integrative philosophy of management of the flows of goods and services and related information's flows through companies which are integrated in the 
processes of supply chain management. Supply chain management includes all business processes and activities and in particular, new products' development of (Koulikoff-Souviron M., Harrison A.2000).

The essence of the classic supply chain is a supply of raw materials and then processing them into finished goods (in one or several companies), transporting them to the warehouses for storage and then transport them to the final recipients of these products or goods. The traditional supply chain focuses on manufacturing processes, transportation and supply, apart from issues related to environmental protection. In the traditional supply chain issues which are omitted from the environmental point of view may help to reduce its degradation. One such issue is the acquisition of raw materials, the classic supply chain does not take into account whether the raw materials are extracted: from renewable sources or with respect to the environment, an example here might be a stretch of rainforest in Cameroon. The issue related to transportation of raw materials, in a classic supply chain, is not taken into account whether a particular type of transport is at least harmful to the environment. Here might be an example the using of road transport which emits a large amounts of carbon dioxide into the atmosphere instead of using rail transport.

However, due to increasing awareness on environmental protection, showing from both sides: the clients side and the companies', the number of activities in the supply chain, which are harmful for the environment, will decrease. Thus arose the so-called. "Green" supply chain, which has been widely discussed in the next section of this article.

\section{Green Supply Chain}

As already mentioned, today almost all companies operating in the market face the challenges which is get the balance between their activities and the environment. Today's market for goods and services market is highly competitive, yet is a market which draws much attention to the aspects of environmental protection, ranging from government regulation through consumer attitudes to the moral. Consequently, companies face the need to change the philosophy of their actions (Beamon B.M., 1999).

Research on "green" supply chains have focused mainly on environmental aspects, the relationship occurring between the principles of supply chain operations, and activities (cooperation and assessment) undertaken by managers, suppliers and consumers. Already in 1995, Murphy in his study proved that $60 \%$ of managers were confident that it is very important to take into account the environmental aspects for all company's activities. In turn, Handfield and Nichols stressed that environmental aspects play a very important role in the management of supply chains. In contrast, van Hoek pointed out the differences which exist between the concept of reverse logistics and "green" supply chains. Namely, the "green" supply chains relates to activities such as reducing sources of waste and resources of consumption, but they are not typical processes for reverse logistics processes (Zhong H., 2006).

The creation of "green" supply chain integration is a process in which the environmental aspects are taking into account in every supply chain activities such as: decisions regarding sourcing of raw materials and creating long-term relationships with suppliers (Gilbert S., 2001). In addition, there are three main approaches that are involved in the creation of "green" supply chain: environment, strategy and logistics (fig. no. 2) (Hwa T.J., 2001). 


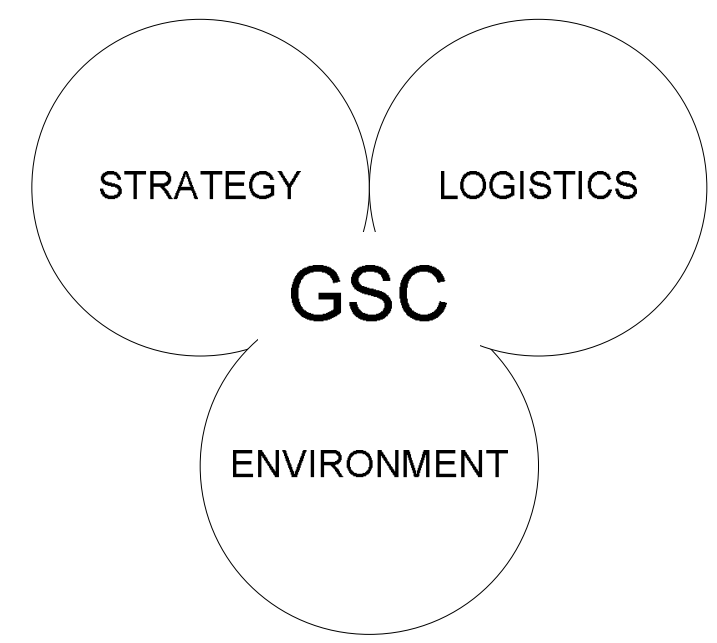

Fig. no. 2. Approaches of Green Supply Chain

Source: Author's elaboration based on Nunes B., Marques S., Ramos R., "A theoretical approach for green supply chain”, Federal University Do Rio Grande Do Norte, Brazil 2004.

The creation of "green" supply chain refers to taking action in these three areas, because GSC is directly linked to environmental protection, together with the strategy, because actions are considered for a long-term period, and logistics - as these activities relate to the management of raw materials, distribution, storage and well as recycling and waste management. The creation of "green" supply chain benefits a single business at the same level as for the entire national economy. In the case of a single organization, the creation of "green" supply chain makes it a significant competitive advantage in decreasing the costs (to create new markets for businesses), more organic and better cooperation with the suppliers. Moreover, at the national level, green supply chains can help to change the market's orientation to become more "green", together with the creation of incentives for small and medium-sized enterprises to implement right practices to improve environmental protection (Gilbert S., 2001).

Activities of "green" supply chain are addressed to the four areas found in the traditional supply chain, such as upper and lower flows, and the activities occurring within the organization and logistics processes (Emmett S., Sood V., 2010):

- The company's activities in the field of production might be connected, for example, with the Green Design, Green Procurement or cooperation with the suppliers to convince them to be more green" in their actions,

- Following-up the businesses on the activities associated with the products' consumption until their total use. Is included here, for the business activity, the recovery and recycling processes, waste management and inventories' disposal from the defaulting companies' warehouses ,

- The activities taking place within the company, "green" supply chains are focused on the activities such as Green Design, Green Green Packaging and Production,

- The logistics processes are distinguished by activities such as JIT (Just-In-Time), fulfillment, lot size management, quality management, and all of them are closely related to the environmental aspects.

In the next part of the article, the examples of companies operating in a various industries, together with their activities, which have a significant impact to create a "green supply chain, will be presented,

\section{Green Supply Chain in the enterprises}

Below are presented a few companies which have a full awareness of environmental responsibility, by taking actions whose effects have a huge influence to transform their supply chain into a green supply chain. 
Company A - it is a company operating in the airline industry. It attaches a great importance to cooperation with their suppliers in terms of environmental protection. The company is the founder of action leading to the creation of a specific forum, which takes place every 18 months. On this forum the views and ideas of individual departments are exchanged, it causing the establishment of cooperation leading to solving environmental problems and challenges faced by companies with similar activities. During the forum, company delegates about 40-50 people, along with the representatives of other companies, they exchange views on environmental issues, such as product life-cycle assessment, and establish a cooperation in order to eliminate these problems. Additionally, the company implemented a system of one-to-one collaboration with suppliers, helping them to find a substitute for material (dangerous for the environment), which are environmentally friendly. In some cases, suppliers provide the company working drawings of projects in order to obtain their comments on the use of parts or materials are not harming the environment. In this way, suppliers of raw materials, become a co-authors in the design of new equipment and become an important part of the activities in the Green Design Process.

Company B - it is a company operating in the automotive industry. This company requires ISO 14001 certification from all its suppliers. This certification is a standard for environmental management and its possession constitutes proof that the company is taking actions which are not detrimental to the natural environment. Requirement for companies is that by 2013, all the collaborators and contractors obtain this certificate. To make it easier, the company has developed a Awareness Training guide, which has tips and describes its experience in obtaining ISO 14001 certification. The company has also developed a program for reusable packaging in order to reduce the number of packs used. As a member of World Excellence Award, the company created the Environmental Recognition title, which is awarded to suppliers for the actions which are an expression of oversized care about the environment. The company is also the founder of Environmental Global Supply Management Forum which the main aim is to develop initiatives in a global supply chains, forum participants are the suppliers of many international companies and their main target is to create an uniform set of environmental requirements as well as tools and trainings.

Company $\mathrm{C}$ is a service company, but despite this, it seeks to create "green" supply chain as the previous ones. This company has created a program for sustainable fishing and, also, cooperate with the manufacturer packaging. For several years, the company has been a partner for several of its key suppliers who are manufacturers of the main materials for the company. Together with producers, the company has developed a balanced performance card which is a monitoring tool most affecting environmental activities such as waste management, energy consumption, the impact on water resources and air. This card has been used in several companies, cooperating with the company, and its use contributed to a smooth control. Currently this tool, the card of sustainable results, is being implemented for all enterprises cooperating with the company.

Company D - it is a company operating in the chemical industry, but for the sake of the nature of its activities, it benefits from agricultural crops. Several years ago, the company launched an initiative for sustainable agriculture, aimed at introducing more sustainable practices for agricultural activities. To this end, the Advisory Board has established consisting of external experts, from large, having important environmental groups, universities and research institutes. These experts create a group of independent advisors. In cooperation with the experts, the company has created 10 indicators, examining the level of sustainability in agriculture. The first studies using these indicators have been carried out on five types of farming: tea plantation, palm oil, crops, spinach, tomato and peas. Following this study, a solution that enabled farmers to reduce the amount of previously applied pesticides and fertilizers has developed, and also helped to reduce the level of water demand. Currently, the company is working on the largest possible number of farmers participated in the initiative and created to introduce the practice of sustainable development for all crops conducted by them. 


\section{Conclusion}

In order to satisfy today's customer demands, it is not enough to offer cheap and good product, the consumer today, also draws much attention to whether a product was manufactured and delivered in a manner which does not adversely affect the protection of the environment. Also, the packaging of the product shows that, the company is guided by the good of the environment. True, most "environmentally conscious" customers are coming from the rich countries. Customers coming from poor countries, pay no attention to either the quality of our products nor are they environmentally friendly nature, this type of customer is only interested in the offered price of the product. However, despite the global trend is just so. "Environmental awareness" and firms seeking to meet the demands of customers are forced to introduce measures to protect the environment. It should also be noted that pro-environmental behavior, or even detrimental to the environment, and also reflected on the financial performance of companies and hence, the value of shares of such companies and investors are getting rid of his shares. An example of such an undertaking may be the British petrol company. As a result of its negligence and not responding to initial oil spill into Gulf of Mexico, it was forced to pay 20 million dollars to fill the compensation to the people who have suffered the greatest losses as a result of the leak and to perform actions to restore an ecosystem that has been completely destroyed. However, in addition to improving economic performance and build a positive corporate image among consumers, "green" supply chain allows the realization of goals such as reduction or complete elimination of hazardous materials that are used both in industry and agriculture, improvement and implementation of ecology behavior, systems design, equipment, machinery and long-term relationships, which in time will bring tangible environmental and economic benefits. One of the key managers said: "activities related to environmental protection have a positive economic data reflected in the company over a long period of time. In a nutshell - Ecological behavior brings profits".

\section{References}

1. Bagchi P.K., 2000. On measuring supply chain competency of nations: A developing country perspective. Cardiff LERC,

2. Beamon B.M., 1999. Designing the Green Supply Chain, in Logistics Information Management, vol 12 ,

3. Chopra S., Meindl P., 2003. Supply Chain. NJ., Second Edition, Prentice Hall,

4. Christopher M., 1998. Logistics and supply chain management: Strategies for reducing costs and improving service, London Financial Times - Prentice Hall,.

5. Emmett S., Sood V., 2010. Green Supply Chain, UK., John Wiley\&Sons.

6. Ganesha R., Harrison T., 1995. An Introduction to Supply Chain Management, Department of Management Sciences and Information Systems, Penn State University

7. Gilbert S., 2001. Greening Supply Chain: Enhancing Competitiveness Through Green Productivity, Taiwan Taipei,

8. Hugos M., 2011. Essentials of Supply Chain Management, NJ., John Wiley\&Sons.

9. Hwa T.J., 2001. Green Productivity and Supply Chain Management, Greening Supply Chain: Enhancing Competitiveness Through Green Productivity, Taiwan Taipei,

10. Koulikoff-Souviron M., Harrison A., 2000. A model of perspectives on supply chain management, Cardiff LERC,

11. Lambert D., Stock J., Ellram L., 2001. Fundamentals of Logistics Management, Boston McGraw-Hill,

12. Mentzer J., Dewitt W., Keebler J., Min S., Nix N., Smith C., 2001. What is Supply Chain Management?, in Supply Chain Management, Mentzer J. (ed)., Sage Publications

13. Nunes B., Marques S., Ramos R., 2004. A theoretical approach for green supply chain, Brazil Federal University Do Rio Grande Do Norte.

14. Zhong H., 2006. Model and algorithms for supply chain Network with Bi-directional floks, NJ., The State University of New Jersey. 